\title{
Ileal Dieulafoy lesion arose 15 years after partial small bowel resection for meconium obstruction of the neonate: a case report
}

\author{
Maho Iwamoto ${ }^{1}$, Tsugumichi Koshinaga ${ }^{2 *}$, Eri Fujita ${ }^{2}$, Manabu Hanada ${ }^{2}$, Shuichiro Uehara ${ }^{2}$ and \\ Mitsuhiko Moriyama'
}

\begin{abstract}
Background: Anastomotic or perianastomotic ulcers present with symptoms such as chronic anaemia and occult bleeding as long-term complications of bowel resection performed in infancy.

Case presentation: Herein, we describe a 15-year-old girl with a history of surgery for meconium obstruction without mucoviscidosis in infancy who was hospitalized with chief complaints of presyncope and convulsions. Seven hours after admission, she developed melena and went into shock. An emergency laparotomy was performed, and a Dieulafoy lesion was detected near the site of ileal anastomosis from the surgery that had been performed during infancy.

Conclusions: Although overt massive lower gastrointestinal bleeding necessitating emergency care is rare in the long term after infant bowel resection, Dieulafoy lesions can cause serious bleeding, requiring rapid life-saving haemostatic procedures.
\end{abstract}

Keywords: Ileal Dieulafoy lesion, Perianastomotic ulcer, Meconium obstruction, Small bowel resection, Case report

\section{Background}

Among the long-term complications of infant bowel resection, including necrotizing enterocolitis (NEC), anastomotic and perianastomotic lesions are relatively rare [1]. Anastomotic and perianastomotic ulcers are usually detected during investigations for chronic anaemia or faecal occult blood, and the diagnosis is often delayed by several years. However, in rare cases, ulceration may develop rapidly with massive life-threatening bleeding requiring emergency treatment [2].

*Correspondence: koshinaga.tsugumichi@nihon-u.ac.jp

${ }^{2}$ Department of Pediatric Surgery, Nihon University School of Medicine,

30-1 Oyaguchi-Kamicho, Itabashi-ku, Tokyo 173-8610, Japan

Full list of author information is available at the end of the article
Dieulafoy lesions are detected as protruding vessels within a minute mucosal defect or within normal surrounding mucosa. Furthermore, Dieulafoy lesions in the small bowel are uncommon in both children and adults. However, all cases present with overt bleeding, necessitating blood transfusions for serious lower gastrointestinal bleeding that generally requires rapid life-saving haemostatic procedures [3]. We report a 15-year-old girl with a history of surgery for meconium obstruction without mucoviscidosis in infancy who rapidly developed massive bleeding from an ileal perianastomotic Dieulafoy lesion and required emergency laparotomy for haemostatic procedures. 


\section{Case presentation}

A 15-year-old girl born prematurely with a low birth weight (696g) developed meconium obstruction without mucoviscidosis when she was 5 days old. A 3 -cm section of her small intestine, including a stenotic lesion $35 \mathrm{~cm}$ from the ligament of Treitz, was resected. An ileostomy was performed $65 \mathrm{~cm}$ from the ligament of Treitz. The ileostomy was reversed 6 months later, with no further complications.

A day prior to the current presentation, the patient experienced intermittent lower abdominal pain and was emergently transported to a local hospital with presyncope and convulsions, which both occurred at 07:00 on the day of the consultation. There were no abnormal findings on head computed tomography (CT) or abdominal ultrasonography. Her haemoglobin level was $11.8 \mathrm{~g} / \mathrm{dL}$ (reference range: $11.6-14.8 \mathrm{~g} / \mathrm{dL}$ ). The patient was sent home. Massive melena occurred at approximately 14:00. Furthermore, she had difficulty maintaining an upright position and was therefore again urgently transported to the local hospital. Her haemoglobin level had decreased to $6.7 \mathrm{~g} / \mathrm{dL}$ over the $7-\mathrm{h}$ period since her morning visit to the hospital. Although blood transfusion was started, massive melena persisted, and she was transferred to our hospital at 23:00. The patient's height and weight were $160 \mathrm{~cm}$ and $45 \mathrm{~kg}$, respectively. Her Glasgow Coma Scale score was 14/15 (eye opening 3, best verbal response 5 , best motor response 6), her blood pressure was $109 / 51 \mathrm{mmHg}$, and her pulse was $76 \mathrm{bpm}$ in the Trendelenburg position. However, her blood pressure dropped to $73 / 36 \mathrm{mmHg}$, her consciousness further decreased, and she went into shock during the examination. Mild oppressive pain in the lower abdomen was noted. There was no increase in C-reactive protein, and the patient also tested negative for coronavirus, norovirus, adenovirus, and faecal bacteria. Contrast-enhanced abdominopelvic CT examination showed massive bleeding in the colon, but the source was not identifiable. The patient was subsequently diagnosed with haemorrhagic shock due to lower gastrointestinal bleeding. Thereafter, emergency endoscopy was performed under general anaesthesia. In the operating room, systolic blood pressure dropped into the 60s, necessitating an intraoperative transfusion of $1600 \mathrm{~mL}$ of blood. Although no abnormalities were detected in the upper gastrointestinal tract, lower gastrointestinal endoscopy revealed massive blood flow from the terminal ileum, and the patient was diagnosed with small bowel haemorrhage. The decision was made to perform open surgery. Intraoperative findings included irregular dilation in the ileum $40 \mathrm{~cm}$ from the ileocecal junction, and a scar presumed to be the anastomotic site was also noted (Fig. 1). Dark red stagnant intestinal content was clearly observed on fluoroscopy. An incision

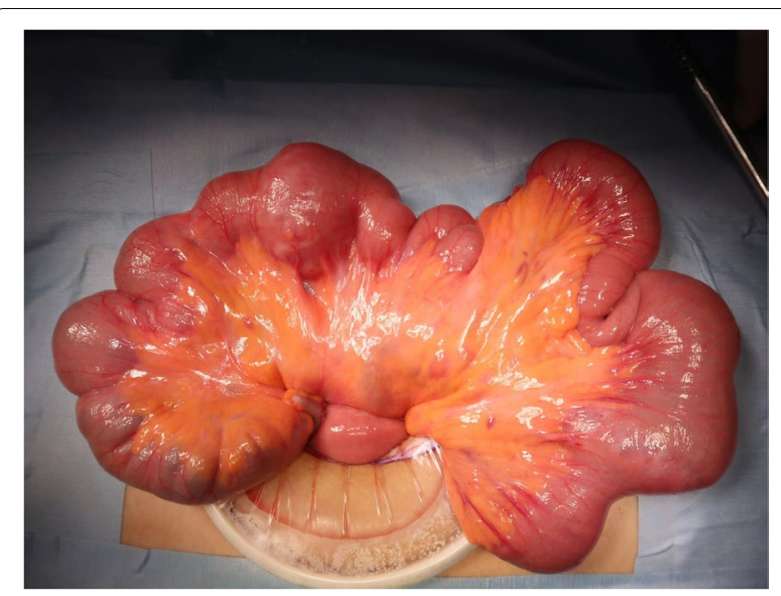

Fig. 1 Surgical findings: Irregular intestinal dilation and dark-red stagnant intestinal content were observed in the ileum $40 \mathrm{~cm}$ from the ileocecal junction. A scar assumed to be the anastomotic site from prior surgery was noted at the same site

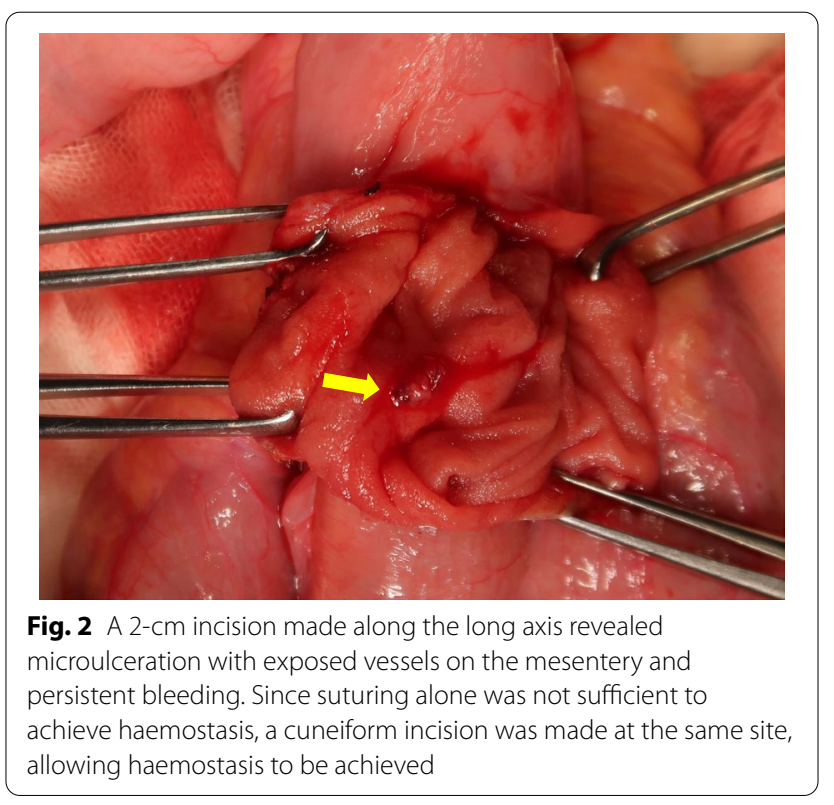

made in the direction of the long axis revealed microulceration with exposed vessels on the mesentery and persistent bleeding (Fig. 2). Since suturing alone was not sufficient to achieve haemostasis, a cuneiform incision was made at the same site, and haemostasis was achieved. Histopathological examination of the surgical specimen showed microulceration with a partial epithelial defect and inflammatory cell infiltration (Fig. 3). No abnormalities were observed in the surrounding membranes. An ileal Dieulafoy lesion was diagnosed based on the appearance of slightly distended arteries and veins in the submucosa of the ulcerated site. The postoperative course 


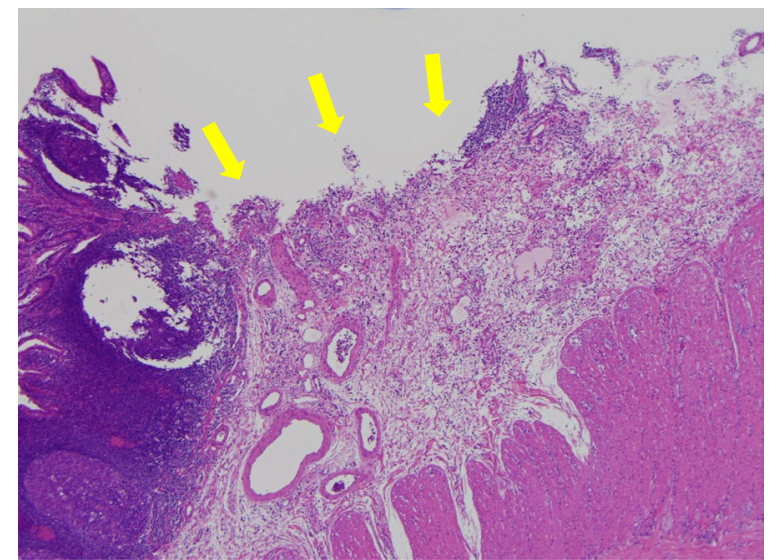

Fig. 3 Intraoperative histopathological findings: A $25 \times 20 \times 10 \mathrm{~mm}$ specimen of the small bowel consistent with ulcer; HE $4 X$ magnification. Microulceration, with a partial epithelial defect and inflammatory cell infiltration, was detected. A slightly dilated artery was identified in the submucosal layer [yellow arrow]

HE: haematoxylin and eosin staining

was uneventful. The patient was discharged on day 11 of hospitalization. She recovered well enough to participate in her school's athletic competition 2 months later.

\section{Discussion and conclusions}

Acute massive lower gastrointestinal bleeding, as in our present patient, is a rare long-term complication after infant bowel resection.

We treated a 15-year-old girl who had experienced rapid onset of massive bleeding from an ileal perianastomotic Dieulafoy lesion and required an emergency laparotomy for haemostatic procedures. She had a history of surgery for meconium obstruction without mucoviscidosis in infancy. It is important to keep anastomotic or perianastomotic ulcers in mind in patients who have a history of intestinal resection during the neonatal period.

The incidence of symptomatic anastomotic ulcers in the paediatric population is approximately $0.3 \%$, and such ulcers are a relatively rare complication of bowel resection [1]. However, anastomotic or perianastomotic ulcers are known to cause chronic anaemia and occult bleeding, which are both potential long-term complications after bowel resection in infancy. Sudden massive lower gastrointestinal bleeding is rare. However, Dieulafoy lesions can produce serious lower gastrointestinal bleeding requiring rapid life-saving haemostatic procedures [2].

As our patient initially presented with presyncope and convulsions, gastrointestinal bleeding was not suspected at the first visit. However, melena manifested $7 \mathrm{~h}$ later, and she went into shock $9 \mathrm{~h}$ thereafter. This patient's course showed that a perianastomotic Dieulafoy lesion can be life-threatening and that an urgent haemostatic procedure is required. Sudden massive bleeding might render children especially susceptible to haemodynamic instability, and the onset may have an atypical course. Caution is thus required in patients with a history of abdominal surgery in the neonatal period, even those who have been well over the long term since the operation.

To our knowledge, this is the second report describing a patient who developed sudden massive lower gastrointestinal bleeding long after surgery performed in infancy [2].

Our search of PubMed from 1992 to 2020 for anastomotic or perianastomotic ulcers in paediatric populations, with the search terms "anastomotic ulcers", "perianastomotic ulcers", "infant" and "neonatal", yielded nine reports in English describing the symptoms of these lesions (Table 1) [1, 2, 4-10]. Of the 35 cases presented in Table 1, including ours, two had a sudden onset, while the onset was more gradual in the other cases. Of all the cases, $60 \%$ had no symptoms of overt bleeding, $66 \%$ eventually had to undergo surgery, and 59\% developed recurrences during follow-up. Some reports described little or no follow-up after the operation performed in infancy, but this may not be clinically appropriate. Given the high percentage of recurrent cases, regular follow-up is highly recommended for children who undergo surgery in infancy [2].

Video capsule endoscopy and double-balloon endoscopy have both been reported to be safe and effective in children as endoscopy methods for the small intestine. Video capsule endoscopy might be useful as postoperative follow-up for children because it is easy and noninvasive, and a patency capsule test can reduce the risk of retention [10-12].

The pathogenesis of Dieulafoy lesions involves both congenital and acquired factors, such as abnormal distribution and dilation of submucosal capillaries, microaneurysms, and arteriovenous malformations combined with mucosal injury secondary to mechanical factors and other causes [13, 14].

The pathogenesis of the lesion in our present case was a perianastomotic site from the surgery performed in infancy. The patient also suffered from intermittent lower abdominal pain the day before the visit, suggesting microulceration caused by mechanical triggers as well as changes in the vascular distribution near the anastomotic site as the probable underlying causes. Moreover, we suspected that intestinal ischaemia occurred during the operation performed when she was an infant.

We conclude that although sudden massive lower gastrointestinal bleeding requiring emergency care is a rare long-term complication after infant bowel 
Table 1 Reports of anastomotic or perianastomotic ulcers after infant bowel resection in children

\begin{tabular}{|c|c|c|c|c|c|}
\hline Case & Author & Primary condition & Symptoms at onset & Final treatment & $\begin{array}{l}\text { Recurrence } \\
\text { while being } \\
\text { treated }\end{array}$ \\
\hline 1 & Hamilton & NEC & Anaemia, FOB & Surgery & Yes \\
\hline 2 & & Gastroschisis & Abdominal pain, melena, IDA & Surgery & No \\
\hline 3 & Paterson & NEC & IDA & Medication & No \\
\hline 4 & Bhargava & NEC & Anaemia, FOB & Surgery & No \\
\hline 5 & Sondheimer & NEC & Acute lower GI bleeding & Surgery & Yes \\
\hline 6 & & NEC & Acute lower Gl bleeding & Medication & $\mathrm{N} / \mathrm{A}$ \\
\hline 7 & & NEC & Abdominal pain, diarrhoea, FOB & Surgery & Yes \\
\hline 8 & & NEC & Abdominal pain, diarrhoea, FOB & Surgery & Yes \\
\hline 9 & & NEC, hernia & Anaemia, FOB & Surgery & No \\
\hline 10 & & NEC & Anaemia, FOB & Surgery & Yes \\
\hline 11 & Arnbjornsson & Gastroschisis, atresia & Loose stool, anaemia, melena & Medication & Yes \\
\hline 12 & Ceylan & NEC & Anaemia, FOB & Surgery & Yes \\
\hline 13 & & Gastroschisis & Abdominal pain, melena, IDA & Surgery & Yes \\
\hline 14 & Charbit-Henrion & Gastroschisis & IDA & Medication & Yes \\
\hline 15 & & NEC & IDA & Surgery & Yes \\
\hline 16 & & Gastroschisis, NEC & Asthenia, IDA & Surgery & Yes \\
\hline 17 & & Gastroschisis & IDA, rectal bleeding & Surgery & Yes \\
\hline 18 & & Gastroschisis & IDA & Surgery & Yes \\
\hline 19 & & Bladder extropy & IDA & None & No \\
\hline 20 & & Atresia & Acute IDA & Surgery & Yes \\
\hline 21 & & Atresia & Acute IDA & Surgery & Yes \\
\hline 22 & & NEC & IDA & Surgery & Yes \\
\hline 23 & Bass & NEC & IDA, FOB & Medication & No \\
\hline 24 & & Atresia & Lower Gl bleeding & Surgery & Yes \\
\hline 25 & & NEC & Lower GI bleeding, anaemia & Surgery & No \\
\hline 26 & & Gastroschisis & Gl bleeding, anaemia & Medication & Yes \\
\hline 27 & Fusaro & Gastroschisis & $\mathrm{IDA}, \mathrm{FOB}$ & Medication & No \\
\hline 28 & & NEC & IDA, rectal bleeding & Endoscopy & No \\
\hline 29 & & NEC & IDA, FOB & Endoscopy & No \\
\hline 30 & & NEC & IDA, melena & Surgery & Yes \\
\hline 31 & & NEC & Rectal bleeding & Endoscopy & No \\
\hline 32 & & Gastroschisis & $\mathrm{IDA}, \mathrm{FOB}$ & Surgery & No \\
\hline 33 & & Atresia & IDA, rectal bleeding & Medication & No \\
\hline 34 & & NEC & IDA, FOB & Surgery & Yes \\
\hline 35 & Our case & Meconium disease & Presyncope, convulsions, melena & Surgery & No \\
\hline
\end{tabular}

Abbreviations: FOB test: faecal occult blood test, IDA: iron-deficiency anaemia, NEC: necrotizing enterocolitis, N/A: not available

resection, Dieulafoy lesions can produce serious bleeding requiring rapid life-saving haemostatic procedures. Long-term follow-up is recommended after surgery in infancy due to the high percentage of recurrences of anastomotic ulcers.

\section{Supplementary Information}

The online version contains supplementary material available at https://doi. org/10.1186/s12887-021-02914-7.

ESM 1.

Abbreviations

CT: computed tomography; NEC: necrotizing enterocolitis. 


\section{Acknowledgements}

We thank the patient and her family. We also thank the Department of Pathology and Microbiology, Nihon University School of Medicine.

\section{Authors' contributions}

$\mathrm{Ml}$ and TK managed the case and wrote the manuscript. EF, MH, SU and MM managed. the case and assisted with content and language editing of the manuscript. All authors read and approved the final manuscript.

\section{Funding}

No funding was obtained for this study.

\section{Availability of data and materials}

The data and materials used and/or analysed during the current study are presented within the manuscript. Any further requests regarding the study data should be addressed to the corresponding author.

\section{Declarations}

Ethics approval and consent to participate

This study was approved by the Ethics Committee of Nihon University School of Medicine, Tokyo, Japan.

\section{Consent for publication}

Written informed consent was obtained from the patient's parents for the publication of this case report.

\section{Competing interests}

The authors have no competing interests to declare.

\section{Author details}

'Division of Gastroenterology and Hepatology, Department of Internal Medicine, Nihon University School of Medicine, 30-1 Oyaguchi-Kamicho, Itabashi-ku, Tokyo 173-8610, Japan. ${ }^{2}$ Department of Pediatric Surgery, Nihon University School of Medicine, 30-1 Oyaguchi-Kamicho, Itabashi-ku, Tokyo 173-8610, Japan.

Received: 17 March 2021 Accepted: 23 September 2021

Published online: 07 October 2021

\section{References}

1. Charbit-Henrion F, Chardot C, Ruemmele F, Talbotec C, Morali A, Goulet $\mathrm{O}$, et al. Anastomotic ulcerations after intestinal resection in infancy. J
Pediatr Gastroenterol Nutr. 2014;59(4):531-6. https://doi.org/10.1097/ MPG.00000000000000472.

2. Fusaro F, Tambucci R, Romeo E, Bagolan P, Dall'Oglio L, Ceccarelli S, et al Anastomotic ulcers in short bowel syndrome: new suggestions from a multidisciplinary approach. J Pediatr Surg. 2018:53(3):483-8.

3. Dulic-Lakovic E, Dulic M, Hubner D, Fuchssteiner H, Pachofszky T, Stadler $B$, et al. Bleeding Dieulafoy lesions of the small bowel: a systematic study on the epidemiology and efficacy of enteroscopic treatment. Gastrointest Endosc. 2011;74(3):573-80.

4. Hamilton AH, Beck JM, Wilson GM, Heggarty HJ, Puntis JW. Severe anaemia and ileocolic anastomotic ulceration. Arch Dis Child. 1992;67(11):1385-6.

5. Paterson CA, Langer JC, Cameron GS, Issenman RM, Marcaccio MJ. Late anastomotic ulceration after ileocolic resection in childhood [corrected]. Can J Surg. 1993;36(2):162-4.

6. Bhargava SA, Putnam PE, Kocoshis SA. Gastrointestinal bleeding due to delayed perianastomotic ulceration in children. Am J Gastroenterol. 1995:90(5):807-9.

7. Sondheimer JM, Sokol RJ, Narkewicz MR, Tyson RW. Anastomotic ulceration: a late complication of ileocolonic anastomosis. J Pediatr. 1995;127(2):225-30

8. Arnbjörnsson E, Larsson LT. Ulceration in an ileocolic anastomosis treated with ranitidin. J Pediatr Surg. 1999;34(10):1532-3.

9. Ceylan H, Puntis JW, Abbott C, Stringer MD. Recurrent perianastomotic ileo/jejuno-colic ulceration. J Pediatr Gastroenterol Nutr. 2000;30(4):450-2.

10. Bass LM, Zimont J, Prozialeck J, Superina R, Cohran V. Intestinal anastomotic ulcers in children with short bowel syndrome and Anemia detected by capsule endoscopy. J Pediatr Gastroenterol Nutr. 2015;61(2):215-9.

11. Lightdale JR, Acosta R, Shergill AK, Chandrasekhara V, Chathadi K, Early D, et al. Modifications in endoscopic practice for pediatric patients. Gastrointest Endosc. 2014;79(5):699-710.

12. Yokoyama K, Yano T, Kumagai H, Mizuta K, Ono S, Imagawa T, et al. Double-balloon Enteroscopy for pediatric patients: evaluation of safety and efficacy in 257 cases. J Pediatr Gastroenterol Nutr. 2016;63(1):34-40

13. Lee YT, Walmsley RS, Leong RW, Sung JJ. Dieulafoy's lesion. Gastrointest Endosc. 2003;58(2):236-43.

14. Nguyen DC, Jackson CS. The Dieulafoy's lesion: an update on evaluation, diagnosis, and management. J Clin Gastroenterol. 2015:49(7):541-9.

\section{Publisher's Note}

Springer Nature remains neutral with regard to jurisdictional claims in published maps and institutional affiliations.

Ready to submit your research? Choose BMC and benefit from:

- fast, convenient online submission

- thorough peer review by experienced researchers in your field

- rapid publication on acceptance

- support for research data, including large and complex data types

- gold Open Access which fosters wider collaboration and increased citations

- maximum visibility for your research: over $100 \mathrm{M}$ website views per year

At BMC, research is always in progress.

Learn more biomedcentral.com/submissions 